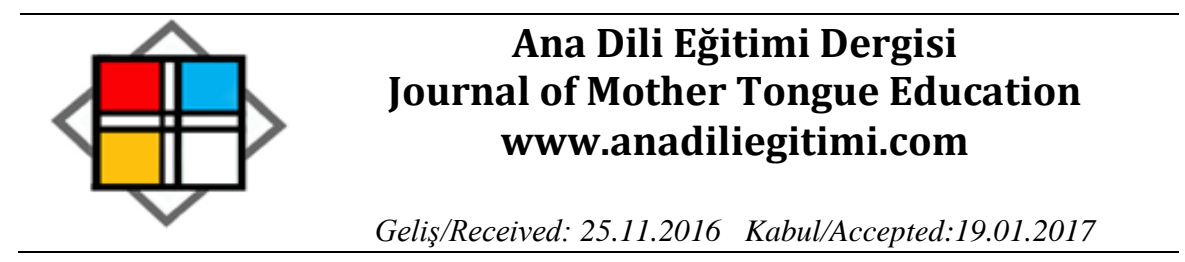

\title{
Elazığ Harput Türküleri Üzerine Bir İnceleme
}

\author{
Fethiye SERT*
}

\section{Öz}

Türküler, bir yörenin kültür özelliklerini içeren en önemli sözlü kültür ögelerinden biridir. Türkülerde kullanılan semboller, işlenen konular, anlatılan duygular; o yörenin sahip olduğu gelenekleri, sosyolojik özellikleri ve kültürü hakkında çok önemli ipuçları vermektedir. Bu amaçla çalışmada, Memişoğlu tarafından 1966 yılında yayınlanan "Harput Ahengi”, Abacı tarafından 2000 yılında yayınlanan "Harput/Elazığ Türküleri" adlı kitaplar ile Yücesu tarafından 1997 yılında tamamlanan "Elazığ-Harput Türküleri" tez çalışmasında yer alarak günümüze kadar ulaşmayı başarmış Elazığ-Harput yöresine ait 147 türkü, şarkı ve uzun hava incelenmiştir. Bu çalışmada türkülerde bulunan sözlü kültür öğeleri, kullanılan isimler, doğa unsurları, ekin ve yiyecek adları, renk adları, kullanılan takı, eşya ve aksesuar isimleri gibi kültür öğeleri, betimsel istatistikler ve grafiksel analizlerle incelenmiş ve böylece Elazığ-Harput yöresinin geleneksel kültürünün, türkülerdeki etkisi belirlenmeye çalışılmıştır. Yapılan çalışma sonucunda eserlerde en fazla kullanılan renk isminin "kara", hayvan isminin "bülbül” ve "kuş", güzellik ürününün ise "kına" olduğu ancak yöreye özgü olan "pestil, pekmez, gakko" sözcüklerinin eserlerin içerisinde çok az yer aldığı görülmüştür. Bununla birlikte Anadolu’nun her yerinde bulunan sözlü kültür ürünlerinden olan "dağ motifi", "kar motifi" ve "evlerinin önü motifi", incelenen eserlerde de görülmektedir. Nihayetinde Elazığ-Harput yöresine ait eserlerin hem yöresel hem de geleneksel kültürün izlerini taşıdığı sonucuna varılmıştır.

Anahtar Kelimeler: Kültür, Elazığ-Harput Kültürü, Türkü, Elazığ Türküleri.

\section{A Study on the Elazığ Harput Folk Songs}

\begin{abstract}
Folk songs are one of the most important elements of oral culture that includes cultural features of a region. The symbols, themes, emotions used in folk songs provide important clues regarding the traditions, sociological characteristics, and culture of the region. In order to identify how local cultural elements are embedded in folk songs, 147 folk songs and ballads belonging to the ElazığHarput region which have survived until the present and are included in the 1966 book "Harput Ahengi" by Memişoğlu, the 2000 book "Harput/Elazığ Türküleri" by Abacl, and the 1997 thesis "Elazığ-Harput Türküleri" by Yücesu, were examined. In this study the oral culture elements found in folk songs such as the names used, names of the elements of nature, crop and food names, names of colors, names of the jewellery items and accessories worn were analyzed using descriptive statistics and tabulated graphically and the influence of the traditional culture of the Elazığ-Harput region on folk songs were attempted to be identified. It was found that in the folk songs examined the most frequent color name was "black", the most frequent animal name was "nightingale", the most frequent cosmetic product name was "henna", but the words "pestil, pekmez, gakko" which are native to the region were rarely seen. In addition, "mountain motif", "snow motif", and "in front of their houses motif" which are oral culture products found all across Anatolia were also seen in these works. As a result, it was concluded that the folk songs belonging to the Elazığ-Harput region carry traces of both local and traditional cultures.
\end{abstract}

Key Words: Culture, culture of Elaziğ-Harput, folk song, Elazığ folk songs

\footnotetext{
* Öğr. Gör., Türk Hava Kurumu Üniversitesi Ankara Havacılık Meslek Yüksekokulu, fsert@thk.edu.tr
} 


\section{Giriş}

Kültür, bir toplumu diğerlerinden ayıran bir maddi ve manevi bir varlık olarak karşımıza çıkar. Topçuoğlu (1975)'na göre nerede bir toplum varsa orada bir kültür doğmuştur. Kültürle toplum ikiz kardeş gibidir, birisi varsa mutlaka öteki de vardır. Çünkü kültür, mutlaka bir nüfusta yaşar; onu yaşatacak bir nüfus yoksa kültür ölüdür ve eğer korunabilirse belgelerde ve kalıntılarda yaşar (Arslanoğlu, 2000). Folklor ise "halkın geleneğe bağlı maddi ve manevi kültürünü kendine özgü metotlarla derleyen, araştıran, sınıflandıran, çözümleyen ve halk kültürü üzerinde değerlendirmeler yapan bir bilimdir" (Tan, 2008: 9). Folklor, kültürün nesilden nesile taşınma vazifesini görmektedir. Tan (2008)'a göre bir olayın veya kültürel ürünün folklor malzemesi sayılabilmesi için halka ait olması, anonim olması, sözlü geleneğe dayalı olması ve nesilden nesile, toplumdan topluma geçerek yayılmış olması gerekmektedir.

Sözlü gelenek, oldukça müphem bir kavramdır. Okuryazar olmayan bir toplumda sözlü gelenek, kuşaktan kuşağa söz aracılı̆̆ıla aktarılan her şeyi -başka bir deyişle kültürün tamamını- kapsar (Goody, 2009). Bu nedenle sözlü kültür ürünleri bir dilin bilinen ilk folklorik özelliklerini temsil eden en önemli unsurlardan biridir. Mani, tekerleme, ninni, ağıt, türkü, atasözü, deyim, destan, masal gibi pek çok tür, sözlü kültür ürünleri olarak karşımıza çıkar. Şarkılar, türküler, ağıtlar, uzun havalar ve halk oyunları; belirli bir ritimle söylenen, musikisi olan ve yıllarca unutulmadan günümüze kadar varlı̆ını koruyabilen sözlü kültür ürünleridir. "Türk folklorunun değerli ürünü olan türküler, Türk halkının yaşantısındaki etkin olayların, duygu ve düşüncelerin kendi kültür ve sanat anlayışının müzik yoluyla anlatımıdır." (Ataman, 2009: 59). Türküler içinde her yörenin kendine ait motiflerini, geleneklerini, dünya görüşlerini ve kendi yaşamlarından izleri görmek mümkündür. Türkü ve ağıtlarda kullanılan ezgiler, seçilen sözcükler, işlenen konular günlük hayattan izler taşır. Bu açıdan Türk folklorunun sözlü kültür ürünlerini üzerinde yapılan çalışmalarla Türk kültürünün korunması ve kullanımının yaygınlaşması mümkündür. Zira folklorun amacı Tan (2008)'ın da ifade ettiği gibi halk kültürünü araştırıp değerlendirerek toplumun sosyo-ekonomik dinamiklerini ortaya çıkarmak, milletin kültür birliğini sağlamak, mahalli kültürü önce milli kültür daha sonra da evrensel kültür hâline getirerek insanlığın ortak kültürüne katkıda bulunmaktır. Bu amaçlar doğrultusunda Elazı̆̆-Harput yöresinde geçmişten günümüze söylenegelen, kültür mirasının çok önemli bir parçası olan türkülerde kullanılan söz varlığı üzerinde yapılacak olan bir araştırma, kullanılan sözcüklerin ve işlenen konuların incelenmesini sağlayacak; Türk kültür ve geleneklerinin ortaya çıkarılmasına, unutulmamasına ve korunmasına katkıda bulunacaktır.

Doğu Anadolu bölgesinde bulunan Elazığ'ın ilk yerleşim birimi Harput'tur. "Elazığ-Harput" mıntıkasının tarihçe bilinen en eski sakinlerini Hurriler oluşturur. Doğu ve Güneydoğu Anadolu'da Neolitik dönemden yani M.Ö. 5000 yıllarından beri devam eden bir Hurri varlığının olduğu ispatlanmıştır (Yıldırım ve Pekşen, 2013). Kuzeyde Kafkasya'dan batıda Malatya-Elazığ hattına, doğuda Urmiye Gölü’nden güneyde Kuzey Suriye’ye kadar olan geniş alanda ortak özellikleri olan bir kültürün 
varlığı saptanmıştır. Ardıçoğlu (1997) ve Alpman (1981), Hurrilerin M.Ö. 2000 yıllarından itibaren Doğu Anadolu'ya yerleştiklerinden ve bir dönem bütün Ön Asya'da hâkimiyet kurduklarından, atı ve atla çekilen harp arabalarını tarihte ilk defa kullandıklarından bahseder. Ayrıca Ünsal (2008), Karaz Kültürünü ortaya çıkaranların Hurriler olduğunu ifade eder. Bütün bu bilgiler Hurrilerin Türk kökenli olduklarının güçlü kanıtları olarak görülmektedir. Harput, M.Ö. 15. yy’dan başlayarak sırasıyla Hurriler, Hititler, Urartular ve Romalılar tarafından ele geçirilmiş; M.S. ise Müslüman Arapların, Bizanslıların, Çubukoğullarının ve Artukoğullarının hâkimiyeti altına girmiştir. 1244 yılında Moğol istilasına uğramış, 1363 yılında ise Dulkadiroğulları tarafından zapt edilmiştir. 1382 yılından sonra Harput, Dulkadiroğulları ile Memlûkların aralarındaki savaşa sahne olmuş, 1465'te Akkoyunlu hükümdarı Hasan Bahadır Han tarafından ele geçirilmiştir. 1507'de Şah İsmail Safevî'nin eline düşen Harput, son olarak 1515'te Osmanlı ordusu tarafından fethedilmiştir (Ardıçoğlu, 1997).

Bu denli farklı toplumların bölgedeki kültüre etkisini sadece tarihî eserlerde değil aynı zamanda yerel musikide de görmek mümkündür. Artukoğulları ve Akkoyunluların kendi dönemlerinde saraylarında mehterhane ve çalgı takımları kurdurdukları, Divan müziği ile birlikte Horasan, Azerbaycan ezgileri icra ettirdikleri hatta Elazığ'da bugün bile yaşayan "divan" makamının onlardan miras kaldığı rivayet edilir. Osmanlı İmparatorluğu zamanında açılan medreselerde de pek çok şair yetişmiş, bu şairlerin divan tarzındaki şiirleri de bestelenerek Harput musikisinde özel yerleri bulunan gazellere, tatyanlara ve müstezatlara güfte yapılmıştır (Abacı, 2013). Bunun dışında Ünal (1989), bu yörede bulunan müziğin bir diğer kaynağının etnik yapı olduğunu; Sunguroğlu (1961) ise özellikle Ermenilerin, çalgı yönünden Harput müziğine birçok yönden katkısı olduğunu, ifade eder (Akt. Abacı, 2013). Yörede, bir dönem Müslümanların çalgı çalmasının yasak derecesinde hoş görülmemesi sebebiyle çalgı ile uğraşanların büyük bir çoğunluğu gayrimüslim olmuştur (Ekici, 2000). Bu nedenle farklı etnik grupların zaman içerisinde Harput müziğine katkıda bulunduklarını söylemek mümkündür.

Harput musikisi, çevresindeki bölgelerden daha köklü bir geçmişe sahiptir. Bu zengin folklorun asıl özgün yönünü ise Anadolu'nun diğer yörelerinden görece farklı biçimde olan yöre müziği oluşturmaktadır (Abacı, 2013). Örneğin “Erzurum'da uzun havaların perdeleri, yani çıkmaları ve yıkmaları, Elazığ'da olduğu gibi belirgin değildir, hatta yoktur denilebilir. Diyarbakır ve Urfa'da ani bir çıkıştan sonra uzun bir yıkış yapılır. Hâlbuki Harput Ağzı'nda ağır ve yüksek havalar söylenirken dört perde üzerinden, düzenli ses dalgaları yapılarak söylenip bağlamasıyla karar kılınır." (Memişoğlu, 1966: 4). Harput musikisinin icrasında görülen bu ayrıcalığın sebebi, müzik kültüründe yalnızca türkü değil aynı zamanda Klasik Türk Müziği, Türk Sanat Müziği, Türk Halk Müziği gibi pek çok türün incelik ve özelliklerini barındırması, olarak gösterilebilir. Örnek vermek gerekirse Harput'ta icra edilen uzun hava ve hoyratların güftelerinde divan şairlerinin gazel ve müstezadları kullanılmıştır (Bulut ve Kazazoğlu, 2012). Bölgenin geçmişinde var olan kültür geçişleri yöre müziğine benzersizlik ve eşsizlik olarak yansımıştır. "Harput müziğinde kullanılan makamların bir bölümü, diğer yörelerde de görülmesine 


\section{Elazığ Harput Türküleri Üzerine Bir İnceleme}

rağmen bir bölümü ise sadece bu yöreye özgüdür. Harput'a özgü bu makamlar: Divan makamı, Elezber makamı, İbrahimiye makamı, Tecnis makamı, Tatvan makamı, Varsak makamı, Muhalif makamı, Müstezat makamı, Kürdî makamı ve Nevruz makamıdır." (Ekici, 2013: 157).

Halk ezgileri özellikle gelişmiş ülkelerde, toplum yapısını çözümleyebilmek, milli birliğe katkıda bulunmak, toplumun çeşitli problemlerine çözüm önerileri üretebilmek amaçlarına yönelik olarak ayrıntılı incelemelere tabi tutulmuştur (Güven, 2009). Harput müzik kültürünü de kullanılan makamlar, eserlerin müzikal analizi, icrası gibi alanlarda inceleyen çeşitli araştırmalar bulunmaktadır. Bunlardan Memişoğlu (1966)'nun Harput Ahengi adlı kitabında Elazığ-Harput yöresine ait türkü ve oyun havaları, makamlarına göre gruplandırılarak verilmiştir; ancak türkülerin söz varlığına değinilmemiştir. Ekici (2000)'nin “Elazığ-Harput Müzik Folkloru” adlı yüksek lisans tezinde sadece Harput'taki geleneksel müziğin icrası, usul ve ezgi yönünden incelenmiş ve ezgilerin notalarına yer verilmiştir. Yücesu (1997)'nun “Elazığ-Harput Türküleri" adlı yüksek lisans tezinde, türküler konularına göre tasnif edilmiş, yapılarına ve ezgilerine göre incelenmiş ayrıca türkü isimleri ve türkü sözleri ayrıntılı bir şekilde listelenmiştir; ancak türkülerdeki söz varlığıyla ilgili herhangi bir bilgi verilmemiştir. Sunguroğlu (19581968)'nun 4 ciltten oluşan ve son basımı 2013'te gerçekleşen "Harput Yollarında" adlı serisinde ise sadece türküler değil, çevre illeri de kapsayan yerel tarih, bölge insanının sosyal hayatındaki unsurlar, düğünler, bayramlar, dini merasimler, yemekler, çocukların eğitimi, yaz ve kış eğlenceleri gibi pek çok durum ele alınmıştır. Abacı (2000)'nın Harput/Elazığ Türküleri, adlı kitabı da önemli bir kaynak olarak kabul edilmelidir. Bu kitabın içeriğinde de yörede kullanılan müzik araçları ve yörenin önemli icracıları bölgenin müziğinin ezgisel yapısı, türkülerin şiirsel yapısı ve türkü içinde kullanılan motifler bulunmaktadır. Bununla birlikte Elazığ-Harput müzik kültürü içinde bulunan türkü, şarkı, hoyrat, uzun hava ve oyun havası içerisinde kullanılan kelimelerin özellikleri ve türleri, yöreye ait kavramlar, kültür öğeleri, türkülerin içeriği, günlük hayattan alınarak kullanılan sözcükler ve yöresel deyişlerle ilgili ayrıntılı bir araştırma yapılan literatür taramasında tespit edilememiştir. Dolayısıyla bu çalışma ile literatüre bu kapsamda katkıda bulunulması amaçlanmaktadır.

Çalışmanın amacı; Elazığ Harput yöresinin geleneksel kültürünün türkülerdeki görünümünü belirlemektir. Bu temel amaç çerçevesinde çalışmanın alt amaçları aşağıdaki gibidir:

- Şarkı, türkü, oyun ve uzun havalarda işlenen konuları ve belirlemek,

- Elazığ-Harput yöresinde söylenegelen sözlü kültür öğelerinden olan Elazığ-Harput müziğinin içerdiği motifleri ve sembolleri tespit etmek,

- Şarkı, türkü, oyun ve uzun havalarda kullanılan söz varlığını belirlemek,

- Şarkı, türkü, oyun ve uzun havalarda kullanılan kavramları ve bu kavramların günlük hayatla ilişkisini ortaya koymak,

- Bölgeye ait kültürel unsurların kullanılıp kullanılmadığını tespit etmek, 
- Yöreye özgü olan olayların ve söylemlerin müziğe nasıl yansıdığını irdelemek.

\section{Yöntem}

Çalışmada kullanılan veriler, literatürde bulunan Elazığ-Harput yöresine ait şarkı, türkü, oyun havası ve uzun havaları içeren Memişoğlu (1966)'nun “Harput Ahengi”, Abacı (2000)'nın “Harput/Elazığ Türküleri” adlı kitaplarından ve Yücesu (1997)'nun “Elazığ-Harput Türküleri” adlı yüksek lisans çalışmasından temin edilmiştir. Bu kaynaklarda yer alan eserlerin tamamı uygulamada kullanılmış ancak bu kaynakların birden fazlasında farklı versiyonları yer alan şarkı, türkü, oyun havası ve uzun havalardan, akademik bir çalışma olması nedeniyle Yücesu (1997)'nun çalışmasında yer alan versiyonu tercih edilmiştir. Eserler, içeriklerine göre tasnif edilmiştir.

Çalışmanın verisini, incelenen eserlerde yer alan sözcükler/kavramlar oluşturmaktadır. Temin edilen verilere betimsel istatistikler uygulanarak içerik analizi uygulanmıştır. "iç̧erik analizinde temel amaç, toplanan verileri açıklayabilecek kavramlara ve ilişkilere ulaşmaktır. İçerik analizinde yapılan işlem, birbirine benzeyen verileri belirli kavramlar ve temalar çerçevesinde bir araya getirmek ve bunları okuyucunun anlayabileceği bir biçimde düzenleyerek yorumlamaktır." (Yıldırım ve Şimşek, 2013: 259). Betimsel istatistiklerden frekans ve yüzde değerleri kullanılmıştır. Sıklık olarak da bilinen frekans değerleri vasıfların tekrar sayısını göstermektedir (Serper, 2004). Aynı zamanda grafiksel analiz yöntemleri kullanılarak elde edilen sonuçlar görselleştirilmiştir. Faydalanılan kaynaklardan alınan eser sayısı Tablo 1.'de verildiği gibidir.

Tablo 1. Çalışmada kullanılan eserlerin alındığı kaynaklar ve sayısı

\begin{tabular}{lc}
\hline Kaynak & Alınan Eser Sayısı \\
\hline $\begin{array}{l}\text { Osman Yücesu, } \\
\text { Türküleri }\end{array}$ & Elazığ-Harput \\
Fikret Memişoğlu, Harput Âhengi & 129 \\
Tahir Abacı, Harput/Elazığ Türküleri & 7 \\
\hline Toplam & 147
\end{tabular}

Tabloda görüldüğü üzere çalışmada 147 adet eser kullanılmıştır. Bu eserlerden 116 tanesi türkü, 11 tanesi oyun havası, 8 tanesi şarkı, 11 tanesi ise uzun havadır. Incelenen eserlerin listesi ekte verilmiştir. Bu eserlerde yer alan su motifi, doğa unsurları, dış mekân ve coğrafi özellikler, bina çeşitleri, ağaç isimleri, meyve ve sebze, ekin ve yiyecek adları, kullanılan çiçek isimleri, hayvan adları, renk adları, giyim-eşya-takı ve aksesuar isimleri türkülerde geçen özel isimler, il ilçe ve yer adları, dinî unsurlar ve akrabalık adları, unvan ve lakaplar tespit edilmiştir. Bu kavramların bir eserde ne kadar tekrar edilirse edilsin sadece bir kez sayılmasına dikkat edilmiştir. Bu şekilde eserlerde ortak olarak kullanılan terimlerin frekans değerleri ve bu frekanslara bağlı olarak hesaplanan yüzde oranları ile tespit edilmiştir. Eserlerin konularına ilişkin bulgular, pasta grafiği kullanılarak görselleştirilmiştir. 


\section{Bulgular ve Yorum}

Bu bölümde çalışmanın verilerinden hareketle araştırmanın alt amaçlarına ait bulgular işlenip yorumlanmıştır. Belirlenen amaçlara uygun olarak yöreye ait musiki eserler incelenmiş; elde edilen bulgular yörenin fiziki, kültürel ve sosyolojik özellikleri göz önünde bulundurularak değerlendirilmiştir.

\section{Türkülerin konularına yönelik bulgular ve yorum}

Elazığ yöresi türküleri, makam ve usullerine göre, bir olaya dayanıp dayanmamasına göre çeşitli sınıflandırmalara tabi tutulmuştur(Memişoğlu, 1966; Sunguroğlu, 2013). Konusuna göre ise Yücesu (1997) tarafından 9 başlığa ayrılmıştır. Bu çalışmada ise biraz daha ayrıntıya girilerek konuların 11 ayrı başlık altında sıralanması uygun görülmüştür. Türkülerin tek bir konuya bağlı kalmaması, türkülerin konularına göre tasniflenmesini zorlaştırmıştır; buna rağmen bir fikir vermesi açısından Elazığ türkülerini, ağılıklı olarak işledikleri konulara göre şu şekilde tasnif etmek mümkündür:

Grafik 1: Elazığ-Harput yöresine ait musiki eserlerde yer alan konular

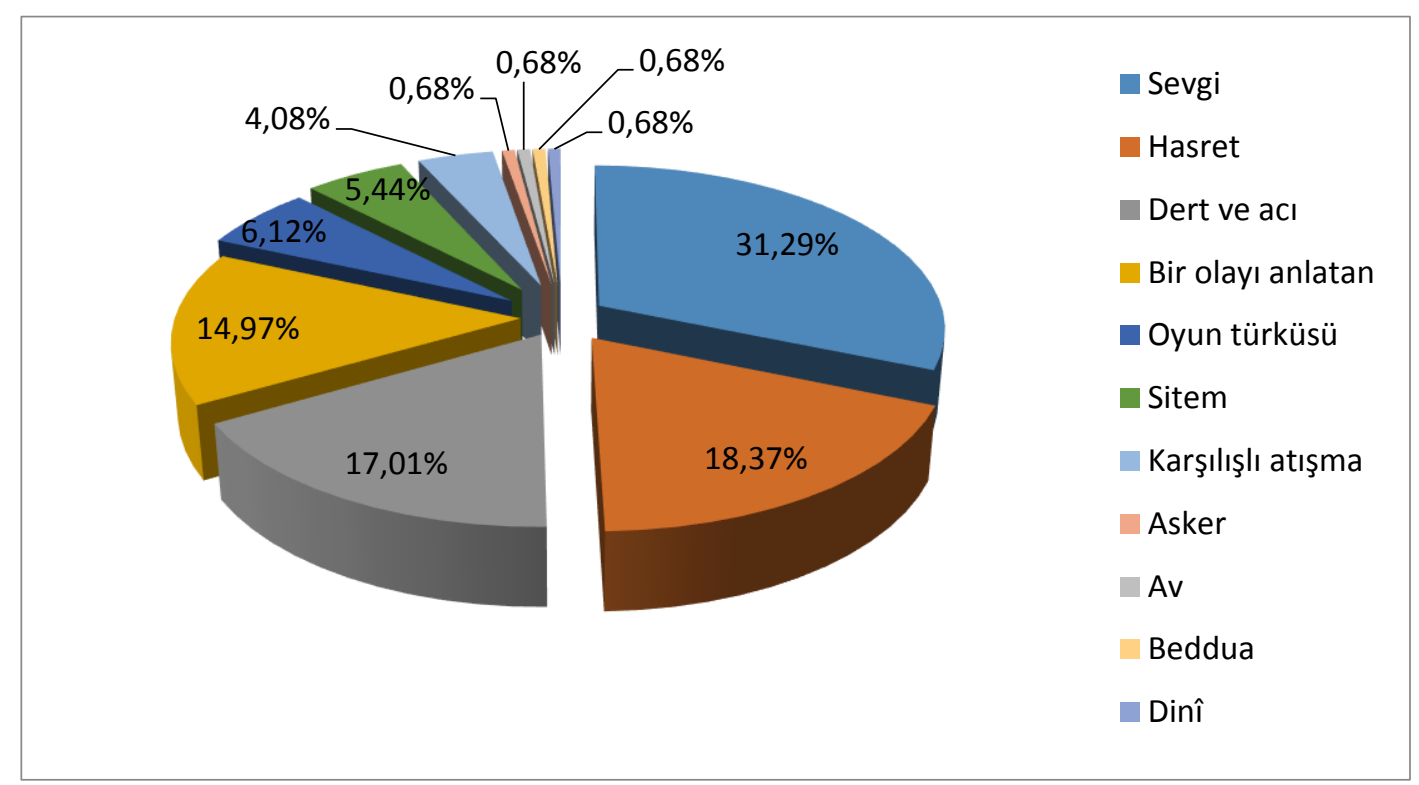

Bir türkü içerisinde bazı durumlarda iki farklı konu işlenebilmektedir. Aynı anda hem sevgi hem de aşk acısı işlenebildiği için genel olarak ağır basan konu, tüm türkünün konusu olarak kabul edilmiştir. Belirlenen 147 eser içerisinde en fazla işlenen tema \%31,2 (46 eser) ile sevgi olmuştur. Sevgiyi \%18,3 ile hasret (sevgiliye olan) takip etmektedir. Elazığ-Harput müziği kapalı bir karakter göstermez. Şarkı ve türkülerde ortak herkesin paylaşabileceği motifler ağır basar, bu nedenle türkülerde ağırlıklı konu aşk gibi evrensel konulardır (Abacı, 2013: 89). Hasret de dert ve acı grubuna girebilir; ancak üzerine yazılan çok fazla türkü olduğu için ayrı olarak sınıflanması daha uygun görülmüştür. Elazığ’da söylenen türkülerin içerisinde asker, beddua, dinî ve av konusunu içeren birer eser bulunmaktadır. Elazığ türküleri içinde din, av ve askere yönelik pek fazla türkünün bulunmadığı görülmektedir. Harput, XIX. yy sonlarındaki Amerika göçleri dışında genellikle göç almıştır. Bu nedenle komşu yöre Eğin'in hemen hemen bütün havaları "gurbet" üzerineyken Harput'ta gurbet türküleri bulunmaz (Abacı, 2013: 90). 
Olay türküleri ise yaşanmış gerçek bir olaydan hareketle yazılan hikâyelerden oluşur. Bu türkülerde özel isimlerinin fazlaca kullanılması, hikâyelerin gerçek hayatta vuku bulduğuna kanıt olarak gösterilebilir. Söz gelimi Ahçik Türküsü, Harput'ta Dabakların Mustafa ile Ermeni Nişan'ın kızı Ahçik arasındaki sevdayı anlatır. Mustafa'nın ailesi, Ahçik'in Ermeni olmasından dolayı bu sevdaya rıza göstermezler. Mustafa da Ahçik'i kendi dinine döndürerek ailesinin rızasını almaya çalışır.
Ahçik'i yolladım Urum iline, Eser bad-ı saba zülfün teline. Gel seni götürem İslam iline. Serimi sevdaya salan o Ahçik Aklımı başımdan alan o Ahçik. (Ahçik Türküsü) (Memişoğlu, 1966: 76)

\section{Türkülerin motiflerine yönelik bulgular ve yorum}

a) Evlerinin önü motifine ilişkin bulgular ve yorum

Elazığ türkülerinde 12 ayrı eserde evlerinin önü motifi geçmektedir. Geleneksel türkü kalıbında sıkça kullanılan bu motif, Harput yöresinde yakılan türkülerde de sıkça görülür.

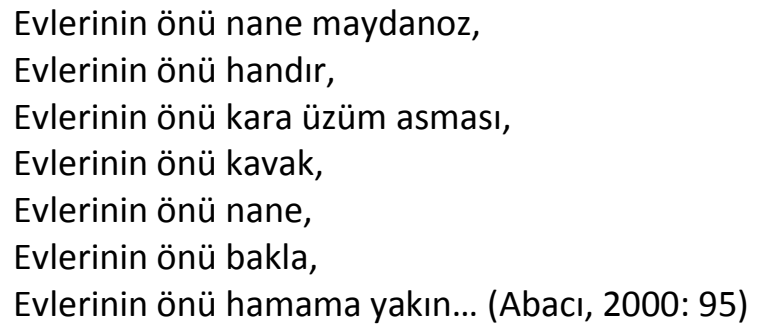

b) Aşk motifine ilişkin bulgular ve yorum

Bazı türkülerde sevdayı ifade edebilmek için çeşitli olay ve durumlara gönderme yapılır. Sevgiliye duyulan aşkın büyüklüğünü göstermek için kendinden önce aşkı ile dillere düşmüş olan kişiler ve olaylar örnek gösterilir. Sevgi denince akla ilk gelen olay gül ile bülbül, akla gelen ilk kişiler ise Leyla ile Mecnun, Kerem ile Aslı'dır. Sevda konulu türkülerde, yörede yaşanan aşk hikâyelerinden gerçek şahısların isimleri kullanıldığı gibi sevda ile ilgili hikâyeler de örnek olarak kullanılmıştır. Elazığ türküleri hem yöresel birikiminden hem de Anadolu kültüründen yararlanmayı ihmal etmemiştir. İncelenen eserlerin 13' ünde gül bülbül motifi'ne 3' ünde Leyla ile Mecnun motifi'ne ve birinde Kerem ile Aslı motifi'ne rastlanmaktadır:

Ne zaman öğretmişler şu bülbülü, Her seher gelir derer gonca gülü.

(Bu Dere Baştan Başa) (Yücesu; 1997: 265)

c) Kar motifine ilişkin bulgular ve yorum

Elazığ ve çevresi, karasal iklimin hâkim olduğu, kışların çetin ve uzun sürdüğü, halkın genellikle tarım ve hayvancılıkla uğraştığı bir bölgedir. Günlük hayatı etkileyen bu özellikler ister istemez türkülere de yansımıştır. Coğrafi olayların özellikle kar motifi'ni türkülerde sıkça görmek mümkündür. Bu motif 


\section{Elazığ Harput Türküleri Üzerine Bir İnceleme}

14 eserde yer bulmuştur. Uzun kışların yaşandığı ve özellikle köylerde aylarca karların kalkmadığı, evler arası ulaşımın karın altından tünel kazarak gerçekleştiği bir yerde, yakılan türkülerde de bu motifin işlenmesi gayet olağan bir durumdur.

$\begin{array}{ll}\text { Kar yağar, kar üstüne, } & \text { Dağları kar aldı getti. } \\ \text { Ölüm bana, ar üstüne. } & \text { Bu benzim sarardı getti. } \\ \text { Bana derler, başka yâr sev, } & \text { Aklım, fikrim var hayâlım, } \\ \text { Yâr sevilmez, yâr üstüne. } & \text { Hepsini yâr aldı getti. } \\ \text { (Kar Türküsü) } & \text { (Sıralı Dağların Karı) (Yücesu, } \\ \text { (Memişoğlu, 1966: 101) } & \text { 1997: 161) }\end{array}$

Su motifine yönelik bulgular ve yorum

Tablo 2. Elazığ-Harput yöresine ait musiki eserlerde yer alan su motifleri

\begin{tabular}{lclc}
\hline Su Motifi & Frekansı & Su Motifi & Frekansı \\
\hline Su & 18 & Bent & 3 \\
Çay & 9 & Deniz & 2 \\
Dere & 8 & Derya & 2 \\
Pınar & 6 & Diğer & 6 \\
Kuyu & 3 & Toplam & 57 \\
\hline
\end{tabular}

Elazığ'ın doğal su rezervi sadece Hazar Gölü'dür. Tarım ve hayvancılıkla uğraşan kesimin su ihtiyacını karşılamak için Cip ve Kalecik Çayları üzerinde barajlar inşa edilmiştir. Keban Barajı́ndan ise elektrik üretimi ve balık yetiştiriciliği şeklinde yararlanılmaktadır. Elazığ ili ve çevresinde karasal iklim hâkimdir ve özellikle ekim zamanında yağmur çok az yağar. Anadolu'nun her köşesinde olduğu gibi bu yörede de suyun çok kıymetli olması, su kaynaklarının fazla bulunmamasına türkülerde su motifinin çokça işlenmesinin sebepleri arasında gösterilebilir. Bunun haricinde eski dönemlerde, çoğu köyde en fazla bir çeşme bulunurdu. Yine köy yerinde günlük hayatının bir parçası olan çeşmeden su taşıma olayı da türkülere şu şekilde yansır:

\section{Eminem gidiyor sabah suyuna,}

Kul köle olmuşum selvi boyuna,

Dünyalar değişmem güzel huyuna.

(Emine Türküsü) (Memişoğlu, 1966: 63)

Su ve ilgili sözcükler toplamda 57 eserde yer almaktadır. İncelenen türkülerin sayısının 147 olduğu düşünülürse neredeyse her üç türkünün birinde su ile ilgili bir sözcüğün bulunduğu sonucuna varılabilir. Diğer bölümünde ise sadece bir eserde yer alan göl, ırmak, sel, akarsu ve bölgedeki akarsulardan olan Fırat Nehri ve Şorşor Suyu'nun isimleri, yer almaktadır. Bölgede deniz ve derya bulunmamasına rağmen bu kelimelerin türkü içerisinde yer alması çok ilginçtir:
Bir dalda iki ceviz,
Denize dalayım mı?
Aramız derya deniz.
Bir balık alayım mı?
Sen orada ben burda
Ay battı, güneş doğdu 
Ne bet kaldı, ne beniz. Daha yalvarayım mı?

(Bir Dalda Türküsü) (Deniz Türküsü)

(Yücesu, 1997: 130) ～(Yücesu, 1997: 259)

Görüldüğü üzere deniz ve derya kelimeleri, ilk türküde abartma öğesi olarak diğer türküde ise ilk iki dizenin birbiriyle uyumlu olması amacıyla mısralarda uyum ve ahenk sağlamak amacıyla kullanılmıştır.

Doğa unsurlarına yönelik bulgular ve yorum

Tablo 3. Elazığ-Harput yöresine ait eserlerde yer alan doğa unsurları

\begin{tabular}{lclc}
\hline Doğa Unsurları & Frekans & Doğa Unsurları & Frekans \\
\hline Kar & 14 & Kum & 4 \\
Yel & 7 & Gölge & 3 \\
Duman & 6 & Yağmur & 3 \\
Buz & 5 & Çamur & 3 \\
Bulut & 4 & Diğer & 2 \\
\hline
\end{tabular}

Yaşam koşulları ve günlük hayatta yaşanan sıkıntı ve durumlar türkülerde de kendine yer bulmuştur. Türkler geçmiş zamanlardan beri doğayla iç içe yaşayan, yaşam koşullarını doğaya göre düzenleyen bir topluluktur. Bu nedenle doğaya ait özellikler 51 eserde kullanılmıştır. Bunların içerisinde en fazla kullanılan doğa unsuru kar'dır. Kar, sadece Elazığ türkülerinde yer almaz, coğrafi özellikler ve yaşam koşulları nedeniyle Anadolu'nun pek çok yerinde söylenen türkülerde benzer simgeleri görmek mümkündür. Kar, bazen sevgilinin tenin beyazlığını bazen de imkânsızlığı sembolize eder. Bunun dışında Tablo 3.'te yer alan Diğer Bölümü'nde bulunan rüzgâr ve kül kelimeleri sadece bir eserde yer almaktadır.

Dış mekan ve coğrafi özelliklere yönelik bulgular ve yorum

Tablo 4. Elazığ-Harput yöresine ait eserlerde yer alan dış mekân ve coğrafi özellikler

\begin{tabular}{lclc}
\hline Dış Mekân & Frekansı & Dış Mekân & Frekansı \\
\hline Dağ & 34 & Bostan & 4 \\
Taş & 19 & Çayır çimen & 3 \\
Bağ & 16 & Diğer & 7 \\
Bahçe & 12 & & \\
\hline
\end{tabular}

Tablo $4^{\prime}$ te belirtilen Diğer Bölümü'nde sahil, ada, orman, harman, zibillik*, ayvan ${ }^{* *}$ ve evlek $^{* * *}$ sözcükleri bulunmaktadır. Türk kültürünün bir diğer göstergesi olan dağ motifi, 34 eserde kullanılarak en fazla kullanılan coğrafi özellik olarak karşımıza çıkmaktadır. Dağlar, Türk mitolojisinde ve kültüründe önemli bir yere sahiptir ${ }^{* * *}$. Ayrıca uzaktan bakılınca insana küçüklüğünü ve güçsüzlüğünü hatırlatır, aşmak istenildiği zaman katlanılması gereken güçlükleri bulunur; bunun

* Zibillik:(Ar. T.) Çöplük, gübrelik. Buran, Ahmet. \& Illhan, Nadir. (2008). Elazığ Yöresi Söz Varlığı. Ankara: Türk Dil Kurumu Yayınları, s. 233.

${ }^{* *}$ Ayvan:(Far.) Balkon, önü açık salon, teras, eyvan. Buran ve illhan, age, s. 11.

*** Evlek:(T.) Tarlada tohum ve sebze ekmek için bölünen kısımlardan her biri. Buran ve illhan, age, s. 69.

${ }^{* * * *}$ Ayrıntılı bilgi için bk. Boratav, Pertev Naili. (2012). Türk Mitolojisi, Ankara: Bilgesu Yayıncılık. 


\section{Elazığ Harput Türküleri Üzerine Bir İnceleme}

yanında akarsu, otlakları, ormanları ile insanoğlunu sığındırma ve besleme yetenekleri vardır(Boratav, 2015: 57). Elazığ her ne kadar bir ova üzerine kurulmuş olsa da bölgenin ilk yerleşim yeri olan Harput, bir dağın yamacına kurulmuştur. Yine Elazığ'daki birçok köy ve kasabaya ulaşmak için pek çok dağı aşmak gerekir; çünkü küçük yerleşim birimleri de dağlar arasında bulunmaktadır. Bu nedenle coğrafi şekiller ve yaşam tarzı, bu yörede söylenen türkülerde de yer alır.
Sıralı dağların karı
Bülbülüm bağ gezerim
Yitirmişim nazlı yârı
Aşığım dağ gezerim.
Yitireli nazı ıârım seni
Yüz yerde yüz yaram var,
Dinmez gönül âh-u zârı.(Sıralı Dağın Karı)
El sanır sağ gezerim.(Bülbülüm Türküsü)
(Yücesu, 1997: 161)
(Yücesu, 1997: 274)

Bina ve Bölümlerine Yönelik Bulgular ve Yorum

Tablo 5. Elazığ-Harput yöresine ait eserlerde bina ve bölümleri

\begin{tabular}{lclc}
\hline Bina & Frekansı & Bina & Frekansı \\
\hline Ev & 21 & Han & 3 \\
Kapı & 11 & Kale & 3 \\
Dam & 9 & Konak & 3 \\
Pencere & 8 & Minare & 3 \\
Oda & 5 & Köprü & 2 \\
Hamam & 4 & Saray & 2 \\
Bent & 3 & Diğer & 13 \\
Değirmen & 3 & & \\
\hline
\end{tabular}

Harput'ta yine aynı adla anılan bir kale bulunmaktadır. Ayrıca şehir, önceki dönemlerde Harput'tan yönetildiği için eskiler, Harput yoluna Saray Yolu demişlerdir. Bu nedenle kale ve saray kelimeleri türkülerde geçer. Elazığ köylerinde evlerin damı düzdür ve dağlık bölgelerde her evin damı kendinden önceki evin avlusu durumundadır. Çamaşır asma, kışlık kurutma, salça yapma gibi pek çok günlük faaliyet, dam üstünde gerçekleştirilir. Elazığ-Harput yöresinde özellikle köy yerinde inşa edilen evlerin damları, günlük hayatta önemli bir yere sahip olduğu için dam kelimesi türkülerde sıkça tekrar edilir.

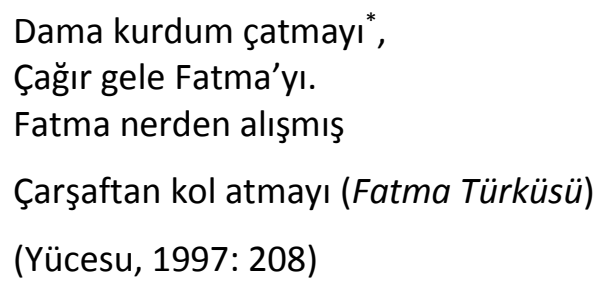

Elazığ yöresinde hamam kültürü, önemli bir yere sahiptir. Eskiden aynı mahallede oturan kadınların her hafta hamama gitmek için belirledikleri bir gün olurdu. Bu nedenle hamam kültürünün izlerini türkülerde de görmek mümkündür. Bunun dışında yörenin zenginleri konakta yaşarlardı. Harput

\footnotetext{
* Çatma:(T.) Yağ çıkarmak amacıyla tulukun asıldığı çapraz dayanmış üç ağaç ya da üç ayaktan kurulu düzenek. Buran ve İlhan, age. s. 37.
} 
ayrıca Bağdat Yolu denen kervan yolu üzerinde önemli bir uğrak merkeziydi. Şehirde çok sayıda büyük ticaret hanı bulunurdu(Abacı, 2013: 23). Bu sebeple türkülerde hamam, konak ve han isimlerine de rastlanılır.

Bir konak yaptırdım, yüceden yüce, İçinde yatmadın, üç gün, üç gece!

Kurbanlar keseydim, göçtüğüm gece.

Ben vuruldum kardaş yine sen sağ ol! (Hakkı Türküsü)

(Memişoğlu, 1966: 86)

Bunların dışında cami, külhan ${ }^{* *}$, meyhane, kilise, karakol, köşk, dükkân, çardak, kışla, hane, çeper, burç, duvar sözcükleri de birer eserde yer almıştır.

Ağaç isimlerine yönelik bulgular ve yorum

Tablo 6. Elazığ-Harput yöresine ait eserlerde ağaç isimleri

\begin{tabular}{lclc}
\hline Ağaç İsmi & Frekansı & Ağaç İsmi & Frekansı \\
\hline Servi/selvi & 7 & Fidan & 2 \\
Meşe & 4 & Nar ağacı & 2 \\
Çınar & 3 & Diğer & 9 \\
\hline
\end{tabular}

Ağaç türlerinden en sık kullanılan "servi ve meşe ağaçları"dır. İki ağaç da iklimden dolayı fazla bitki ve ağaç bulunmayan Elazığ-Harput yöresinde zor hava koşullarına dayanabilen ve sık görülen ağaç türlerindendir. Kurak bir iklimi olduğu için yörede fazla ağaç bulunmadığı için bu alanla ilgili kelimeler toplamda sadece 27 defa zikredilmiştir; ancak ağaç isimlerinde çeşitliliği görmek mümkündür. Çam ağacı, ceviz ağacı, badem ağacı, armut ağacı, incir ağacı, kavak, söğüt, iğde ve mazı ağacı'nın isimlerinin sadece birer eserde yer aldıkları gözlenmiştir.

Meyve ve Sebze Adlarına Yönelik Bulgu ve Yorumlar

Tablo 7. Elazığ-Harput yöresine ait eserlerde meyve ve sebze adları

\begin{tabular}{lclc}
\hline Meyve ve Sebze & Frekansı & Meyve ve Sebze & Frekansı \\
\hline Elma/alma & 9 & Badem/payam & 2 \\
Nar & 6 & Çağla/çağala & 2 \\
Üzüm & 5 & Kabak & 2 \\
Ayva & 4 & Diğer & 11 \\
Erik/erük & 3 & &
\end{tabular}

Tablo 7.'de görüldüğü üzere türkülerde en fazla kullanılan meyve ismi elma ve nar'dır. Bahçesi olan her evde bu ağaçlar muhakkak bulunur. Üzüm de yine yamaçlarda, eğimden dolayı tarımın yapılamadığı ve suyun olmadığı alanlarda ekilir. Ayrıca üzüm ile ilgili olan bağ sözcüğünün Tablo 4.'te belirtildiği gibi 14 eserde geçtiği görülmektedir. Bunun haricinde bölgenin simgesi durumunda olan “öküz gözü” üzüm çeşidinin burada yetişmesi, bölgede bir şarap fabrikasının bulunması ve üzümden

\footnotetext{
${ }^{* *}$ Külhan:(Far.) Hamam ocaklığı. Buran ve illhan, age, s. 141.

* Bağ:(Far) 1.Üzüm kütüklerinin dikili bulunduğu toprak parçası, 2.Meyve bahçesi, TDK. (2005). Türkçe Sözlük, s. 176.
} 


\section{Elazığ Harput Türküleri Üzerine Bir İnceleme}

yapılan pekmez, pestil (basduk, basduh) ${ }^{* *}$ gibi ürünlerin hammaddesi olması, üzümün yöre halkı için önemli bir meyve olmasını sağlamıştır. Tabloda belirtilenler dışında pırasa, biber, mişmiş, armut, kavun, kiraz, vişne, karadut, yemiş, ceviz ve fındık isimleri de birer eserde yer almıştır.

Ekin ve Yiyecek Adlarına Yönelik bulgu ve Yorumlar

Tablo 8. Elazığ-Harput yöresine ait eserlerde ekin ve yiyecek adları

\begin{tabular}{lclc}
\hline Ekin ve Yiyecek & Frekansı & Ekin ve Yiyecek & Frekansı \\
\hline Şeker & 10 & Un & 3 \\
Bal & 9 & Meze & 2 \\
Bade/şarap & 6 & Nane & 2 \\
Aş & 3 & Pamuk & 2 \\
Karanfil & 3 & Pekmez & 2 \\
Tarçın & 3 & Yarpuz $^{* * *}$ & 2 \\
Tütün & 3 & Diğer & 20 \\
\hline
\end{tabular}

Tablo 8.'de ifade edilenlerin haricinde kenger $^{* * * *}$, maydanoz, $_{\text {tevek }}{ }^{* * * *}$, çırpız $^{* * * * *}$, çemen, buğday, arpa, bakla, saman, susam, ekin, şerbet, yoğurt, kaymak, basduk, hamur, yağ, yonca, kebap ve kıyma kelimeleri bir eserde kullanılmıştır. İncelenen türküler içinde ekin ve yiyecek adlarına toplamda 70 eserde rastlanılmıştır. Bu durum, neredeyse her iki türküden birinde ekin ve yiyecek isminin geçtiğini göstermektedir. Elazığ'da yemek kültürü, diğer bütün doğu illerinde olduğu gibi çok gelişmiştir. Zengin bir mutfağa sahip olan yörenin aynı şekilde türkülerde de yiyecek ve yemek malzemelerine çok fazla yer vermesi günlük yaşamın sözlü kültür öğelerinden olan türkülere yansıması olarak karşımıza çıkar. Yalnız, bölgede çokça yapılan pekmezin türkülerde iki defa, pestil'in (bastık) ise sadece bir defa geçmesi dikkat çekicidir. Bunun dışında tahı ürünleri isimlerinin çok az kullanıldığı görülmektedir. İklim ve coğrafi koşullar dolayısıyla bölgede buğday, arpa, pirinç gibi tahıl ekiminin fazla yapılmaması, türkülerde birkaç tahıl isminin sadece birer eserde geçmelerinin sebepleri arasında gösterilebilir. Türküler bu yönüyle günlük yaşamı olabildiğince yansıtmıştır.

Çiçek adlarına yönelik bulgu ve yorumlar

Tablo 6. Elazığ-Harput yöresine ait eserlerde çiçek adları

\begin{tabular}{lclc}
\hline Çiçek Adları & Frekansı & Çiçek Adları & Frekansı \\
\hline Gül & 49 & Çiçek & 4 \\
Dal & 15 & Sümbül & 3 \\
Yaprak & 8 & Diğer & 3 \\
Gonca & 4 & & \\
\hline
\end{tabular}

\footnotetext{
${ }^{* *}$ Pestil: İnce yufka biçiminde kurutulmuş meyve ezmesi, bastık, TDK, age. s. 1600 .

*** Yarpuz: (T.) Dere otu, yaban nanesi. Buran ve İlhan, age, s. 223.

${ }^{* * * *}$ Kenger: (Far.) Bileşikgillerden, yaprakları dikenli yabani bir bitki. Buran ve İlhan, age, s. 128.

${ }^{* * * * *}$ Tevek: (T.) Asma, kavun karpuz gibi bitkilerin dalları. Buran ve Illhan, age, s.204.

****** Çırpız: (T.) Buğday filizi, tarlada çimlenmiş buğday ve arpa, yeni yeşeren buğday, Buran ve illhan, age, s.
} 41. 
Tablo 9.'da belirtildiği gibi en fazla kullanılan çiçek, gül olmuştur. Incelenen türkülerin \%33'ünde(49 türkü) gül kelimesi kullanılmıştır. Gül kelimesinin bu kadar fazla kullanılmasında gül bülbül motifi'nin etkisi büyüktür. Ayrıca Elazığ-Harput müziği Türk Halk Müziği ve Türk Sanat Müziği'nin etkilerini taşımaktadır*. Bu müzik türlerinin karışımı sayesinde yöreye özgü bir yapı ve üslup ortaya çıkar. Bu müzik türlerinin karakteristik özelliklerini yöresel müzikte de görmek mümkündür. Yöreye özgü olan divan makamında bu motife doğal olarak da gül kelimesine rastlamak mümkündür. Yine çiçek adı olmamasına rağmen bitki kavramıyla ilgili olarak dal kelimesi 15 eserde, yaprak ise 8 eserde kullanılmıştır. Bunların dışında menekşe, lale ve karanfil çiçek isimleri ise birer eserde yer alır.

Hayvan adlarına yönelik bulgu ve yorumlar

Tablo 10. Elazığ-Harput yöresine ait eserlerde hayvan adları

\begin{tabular}{lclc}
\hline Hayvan Adı & Frekansı & Hayvan Adı & Frekansı \\
\hline Bülbül & 23 & Arı & 2 \\
Kuş & 11 & Balık & 2 \\
At & 10 & Baykuş & 2 \\
Koyun & 7 & Deve & 2 \\
Güvercin/göğercin & 6 & İt & 2 \\
Keklik & 6 & Kurbağa & 2 \\
Kuzu & 4 & Leylek & 2 \\
Ceylan & 4 & Şahin & 2 \\
Arslan & 3 & Yılan/ilan & 2 \\
Kurt & 3 & Diğer & 11 \\
\hline
\end{tabular}

Tablo 10.'da görüldüğü gibi gül-bülbül motifinin etkisiyle en fazla kullanılan hayvan ismi bülbül olmuştur. Kökleri çok eskiye dayanan ve farklı efsanevi anlatım biçimlerinde konu edilen $a t^{\prime \prime ı n ~ d a ~ T u ̈ r k ~}$ kültüründe özel bir yeri vardır** . At, Türk kültüründe kendine has bir yeri olan ve atalarımızı simgeleyen bir hayvandır. Bunun haricinde bölgede keklik avcılığı çok yaygındır. Öldürmek için değil büyütmek için yakalanan keklik ve güvercin, 6 eserde gözlenmiştir. Leylek ve $k u r t^{* * *}$ figürlerinin Türk kültüründe ayrı bir yere sahip olması, bu isimlerin Elazığ türkülerinde de yer almasının sebepleri arasında gösterilebilir.

Diğer Bölümü'nde belirtilen bit, doğan, fare, horoz, karınca, kartal, koç, pervane, samur, tilki, turna hayvan isimlerine bir eserde görülmüştür. İncelenen türküler içinde hayvan isimleri toplamda 106 eserde zikredilmiştir. Türk toplumunun tarih sahnesine çıktığı ilk dönemlerde geçimini hayvancılık ile sağlaması, söylenen türkülerde hayvan isimlerinin bu denli kullanılmasının sebepleri arasında gösterilebilir.

${ }^{*}$ Ayrıntılı bilgi için bk. Abacı, Tahir. (2013). Harput/Elazığ Türküleri. İstanbul: İkaros Yayınları, s. 40-53.

${ }^{* *}$ Ayrıntılı bilgi için bk. Boratav, age., s. 73-77.

*** Ayrıntılı bilgi için bk. Demir, Necati. (2014). "Türk Kültüründe Yeni Gün(Nevruz) ve Tarihi Alt Yapısı”, Dil Tarih Kültür ve Edebiyat Araştırmaları l. Cilt, Ankara: Edge Akademi, s. 475-488 


\section{Elazığ Harput Türküleri Üzerine Bir İnceleme}

Renk adlarına yönelik bulgu ve yorumlar

Tablo 11. Elazığ-Harput yöresine ait eserlerde renk adları

\begin{tabular}{lclc}
\hline Renk Adı & Frekansı & Renk Adı & Frekansı \\
\hline Kara & 30 & Siyah & 4 \\
Al & 17 & Mavi & 3 \\
Beyaz & 11 & Kır & 2 \\
Mor & 8 & Kırmızı & 2 \\
Yeşil & 7 & Pembe & 2 \\
Ak & 5 & Diğer & 6 \\
Sarı & 4 & & \\
\hline
\end{tabular}

Tablo 11.'de türkülerde geçen renk isimleri açıklanmıştır. 16 renk ismi toplamda 101 eserde kullanılmıştır. Renk isimlerinden en fazla kullanılan kara olmuştur. Kara ve siyah sözcükleri aynı renge karşılık gelmesine rağmen kara, 30 eserde; siyah ise 4 eserde kullanılmıştır. Yine aynı şekilde kırmızı ve al sözcükleri aynı rengi karşılamalarına rağmen al, 17 eserde; kırmızı ise 2 eserde kullanılmıştır. Diğer sözcüklere göre daha fazla kullanılan kara ve al kelimelerinin tek ortak noktası ise ikisinin de kökenlerinin Eski Türkçeye dayanmasıdır*. Tabloda belirtilenler haricinde türkülerde turunç, ala, bedrenk, ela, gül rengi ve gülkurusu renkleri de birer eserde yer almıştır.

Giyim, eşya, takı ve aksesuara Yönelik Bulgu ve Yorumlar

Tablo 12. Elazığ-Harput yöresine ait eserlerde giyim, eşya, takı ve aksesuar

\begin{tabular}{lclc}
\hline Giyim, Eşya & Frekansı & Giyim, Eşya & Frekansı \\
\hline Kına & 12 & Lira & 5 \\
Mendil & 8 & Merhem & 5 \\
Yastık & 8 & Testi & 5 \\
Yüzük & 8 & Hançer & 4 \\
Para & 7 & Düğme & 4 \\
Sürme & 7 & Kefen $^{*}$ & 4 \\
Yazma & 6 & Lüver $^{* *}$ & 4 \\
Çarşaf & 5 & Puşu $^{+* * *}$ & 4 \\
Fincan & 5 & Diğer & 98 \\
\hline
\end{tabular}

Elazığ türkülerinde 114 ayrı giyim, takı, eşya ve aksesuar ismi geçer. Bunlardan vücudun sadece baş ve boyun kısmı için kullanılan eşyalar: çit(yazma), çuha, duvak, fes, hotoz", kalpak, küllah, küpe, peçe, puşu, saç bağı, taç, tarak, yaka, yastık ve yazma'dır. Vücudu örtmek kullanılan eşyalardan atlas(kumaş), basma, çarşaf, don, etek, fistan, gömlek, ipek, kefen, kaftan, kuşak, mantin, pantolon, şalvar ve yamçı $^{* \ddagger}$ kelimeleri türkülerde yer bulur. Ayak için çorap, hırik ${ }^{* * *}$, kundura, papuç ve potin

*Ayrıntılı bilgi için bk. Gülensoy, Tuncer. (2011). Türkiye Türkçesindeki Türkçe Sözlüklerin Köken Bilgisi Sözlüğü I. Cilt. Ankara: Türk Dil Kurumu Yayınları.

${ }^{* *}$ Lüver: Silah, tabanca. Buran ve Illhan, age, s. 145.

${ }^{* * *}$ Puşu:(Far.)Bir tür başörtüsü. Buran ve İlhan, age, s. 175.

*Hotoz:(eskimiş) 1.Kadınların süs için saçların üstüne taktıkları, çeşitli renk ve biçimde yapılmış küçük başlık, 2.Tavus kuşu, tavuk vb.nin başında bulunan tüyler, TDK. (2005). Türkçe Sözlük. Ankara: Türk Dil Kurumu. s. 901.

‡*$^{*}$ Yamçı:(T.) Yağmur ve soğuktan korunmak için kıldan, keçeden yapıımış üst giysisi. Buran ve illhan, age, s. 222.

${ }^{* * *}$ Hırig:(T.) Eskimiş ayakkabı, pabuç. Buran ve Illhan, age, s. 110 
kelimelerini; kesici alet ve av malzemesi olarak ağ, bıçak, çakı, hançer, kafes, kama, kemend(kement), kılıç, kın, kurşun, lüver, makas, neşter, silah ve tüfenk kelimelerini görmek mümkündür. Su ile alakalı gügüm, küze $e^{* * * *}$, sürahi, şişe, tas ve testi kelimeleri bulunur. Günlük hayatta evi sıcak tutması ve ısınmak için kullanılan eşya ve araç gereçlerden çıra, halı, kandil, keçe, kilim, kürk, kürek, post ve yün kelimeleri kullanılmıştır. Bunların haricinde altın(para), anahtar, bardak, beşik, bilezik, cep, çan, çelenk, def(tef), defter, dolap, döşek, düğme, fincan, gergef, gümüş(para), haç, iğne, ilaç, kadeh, kalem, kaşık, kese, kelepçek, kına, kilit, kitap, lira, mendil, merhem, merdiven, para, payton(fayton), piyale, raf, saksı, sofra, sürme, şeve ${ }^{* * * *}$, tarabulus, tepsi, tesbih, top, tokmak, yelpaze, yorgan, yüzük ve zincir kelimeleri türkülerde yer alır. Günlük hayatın türkülere yansıması olarak günlük yaşamın her alanda kullanılan 114 ayrı eşya ve araç gereç ismi, toplamda 199 defa türkülerde yer almıştır.

Özel isimlere yönelik bulgu ve yorumlar

Tablo 13. Elazığ-Harput yöresine ait eserlerde özel isimler

\begin{tabular}{lclc}
\hline Özel İsim & Frekansı & Özel İsim & Frekansı \\
\hline Hayriye & 3 & Hayro & 2 \\
Mecnun & 3 & Henno & 2 \\
Ahmet & 2 & Leyla & 2 \\
Fatma & 2 & Mamo/Mamoş & 2 \\
Güllü & 2 & Nuri & 2 \\
Fide & 2 & Diğer & 44 \\
Hakkı & 2 & & \\
\hline
\end{tabular}

Türkülerde yer alan isimler gerçek hayat hikâyelerinden alınmıştır. Daha önce de belirtildiği gibi Elazığ türkülerinin 22 tanesinde, gerçek bir olay ele alınmış ve işlenmiştir. Bu olayda yer alan sevgililer ve sevgililerin kavuşmasını engelleyen kötü karakterler olmak üzere pek çok özel isim, türkülerde dile getirilir. İncelenen türkülerde 57 ayrı isim, toplamda 70 defa geçmektedir. Yukarıda sıralananlar dışında türkülerde birer kez yer alan diğer isimler ise şunlardır: Agâh, Ahçik, Akif, Aliye, Aslıhan, Ati Hanım, Ayşe, Beşir, Bekir, Dilber, Duriye, Emine, Emrah, Fatoş, Feride, Güllühan, Gülter, Hafo(Hafize), Halit, Hamdi Çavuş, Hamil, Hasan, Hatice, Hayri, Kemal, Kerem, Lefter, Lütfü, Münire, Nadide, Nadir, Nayim, Necibe, Nedim, Neso, Paro, Sara, Seyit Rıza, Süleyman, Şevki, Tahir, Yusuf, Zeynep ve Zeyno(Zinnete). Türkülerde yer alan isimlerin çoğunun, günlük hayatta da olduğu gibi tam haliyle değil de kısaltılarak kullanılması dikkat çekicidir. Öyle ki Hayro ve Heno(Henno) olarak kısaltılmış kelimelerin aslı bilinmemektedir.

${ }^{* * * *}$ Küze:(Far.) Testi benzeri ve pişirilmiş topraktan yapılma, ince uzun ev aracı. Buran ve İlhan, age, s.142.

***** Şeve:(T.) Camdan yapılmış bilezik. Buran ve Illhan, age, s. 195. 


\section{Elazığ Harput Türküleri Üzerine Bir İnceleme}

II, ilçe ve yer adlarına yönelik bulgu ve yorumlar

Tablo 14. Elazığ-Harput yöresine ait eserlerde il, ilçe, yer adları

\begin{tabular}{lclc}
\hline Yer Adları & Frekansı & Yer Adları & Frekansı \\
\hline Harput & 13 & Toptop & 2 \\
Hüseynik & 2 & Diğer & 32 \\
İstanbul & 2 & & \\
\hline
\end{tabular}

En fazla kullanılan Harput kelimesi 13 eserde yer bulmuştur. Hüseynik, Elazığ’da bir mahalle olup (yeni adı Ulukent) adını söylendiği türküye de vermiştir (Hüseynik Türküsü). Toptop, Elazı̆̆'da bir yamaçta bulunan mezarlığın adıdır. Türkülerde uzak diyarları ifade etmek için Anadolu, Bağdat, Isfehan, Frenk ili, Halep, Horasan, Mısır, Musul, Şam, Şark, Türkmen ve Yemen isimleri birer eserde kullanıımıştır. Bunun dışında yerel il, ilçe, köy ve mahalle adı olarak Besni (Adıyaman), Dersim, Hozat, Elazığ, Erzincan, Diyarbekir, ı̆̆ıki (köyü), Kağacık (mahallesi), Kanlıdere, Kayabaşı, Kırkkuyu, Koza, Köğenk (köyü), İslam ili, Urum ili, Uzunçarşı, Perçenç (köyü), Pertek, Sivas ve Teştek'tir (köyü). Olay türkülerinde gerçek hayat hikâyelerinin işlenmesi, muhit olarak gerçek mevkilerin kullanılmasına neden olmuştur.

Dinî unsurlara yönelik bulgu ve yorumlar

Tablo 15. Elazığ-Harput yöresine ait eserlerde dinî unsurlar

\begin{tabular}{lclc}
\hline Dinî Unsurlar & Frekansı & Dinî Unsurlar & Frekansı \\
\hline Allah & 11 & Hakk & 4 \\
İman & 8 & Kâfir & 3 \\
Mevla & 8 & Melek & 3 \\
İnşallah & 5 & Merhamet & 3 \\
Yaradan & 5 & Minare & 3 \\
Bayram & 4 & Diğer & 29 \\
\hline
\end{tabular}

İncelenen türküler içinde her ne kadar konu itibariyle dinî tema içeren sadece 1 (bir) türkü bulunsa da bazı türkülerde, dinî öğeleri temsil eden kelimelerin kullanıldığı görülür. İki eserde rastlanan kelimeler billahi, haram, huri, Hüda, dinsiz, imansız, kıyamet, maşallah, sevap, Tanrı, vallahi; sadece bir eserde rastlanan kelimeler ise arefe, cami, cennet, dua, ecel, ezan, gâvur, gögün yedi katı, haşr, helal, Hz. Süleyman, mahşer, namahrem, namaz, oruç, üç aylar, secde ve vebal'dir. Görüldüğü gibi dinî konulu türkü bulunmamasına rağmen toplumsal hayatın etkisiyle dinî unsurlar toplamda 86 eserde yer bulmuştur. Bu durum, toplumun sosyolojik özelliklerinin türkülere yansımasının örneklerinden biri olarak karşımıza çıkmaktadır. 
Akrabalık adları, unvan ve lakaplara yönelik bulgu ve yorumlar

Tablo 16. Elazı̆g-Harput yöresinde ait eserlerde akrabalık adları, unvan ve lakaplar

\begin{tabular}{lclc}
\hline Akrabalık/Unvan & Frekans & Akrabalık/Unvan & Frekans \\
\hline Kız & 26 & Bacı & 4 \\
Ana & 23 & Bey/beğ & 4 \\
Gelin & 18 & Çoban & 3 \\
Ağa & 15 & Hekim & 3 \\
Oğul & 11 & Sultan & 3 \\
Kardaş/gardaş & 11 & Tabip & 3 \\
Oğlan & 8 & Yosma & 3 \\
Baba & 7 & Diğer & 35 \\
Paşa & 6 & & \\
\hline
\end{tabular}

Gerçek hayat hikâyeleri, Elazığ-Harput yöresinde söylenen türkülerde fazlaca yer aldığı için bu türkülerde gereğinden fazla karakterlere de rastlamak mümkündür.

Sevda türkülerinin ağırlıkta olmasına rağmen akrabalık bildiren isimlerden en fazla kullanılan 2. isim anne olmuştur. Baba kelimesinin görüldüğü türkü sayısı ise 7 'dir. Konusu ne olursa olsun türkülerin içinde anne kelimesinin bulunması, gerçek hayatın yansıması şeklinde de düşünülebilir. Baba figürü her ne kadar evin koruyucusu olsa da ağıt ve türkülerde, sevinç ve üzüntüde ilk olarak anne kelimesi dile getirilir. Bunun dışında, oğul ile oğlan sözcüklerinin karşıı̆ı̆ı aynı olsa da farklı yaş grupları ve kişiler tarafından kullanıldığı için ayrı ayrı tasnif edilmesi uygun görülmüştür. Bu sayede türkünün kim tarafından ve ne için söylediği daha netlik kazanır. Türkülerde oğul sözcüğünü daha çok anneler ve evin büyükleri kullanırken iken oğlan sözcüğü ise genç kızlar tarafından sevdalandığı erkekler belirtmek için kullanılmaktadır. Bunların dışında Ağa ve bey/beğ, köy hayatında önemli bir konuma sahiptir, gücü ve kudreti simgeler. Bu iki unvan da ya iyi veyahut kötü karakter olarak türkülerde yer almaktadır.

Tabloda belirtilenler dışında askerler için çavuş, sipahi, redif, piyade, zabit; bir mesleğe tabi olanlar için bağmancı, davulcu, defçi, doktor, keşiş ve zurnacı isimleri kullanılmıştır. Bazı türkülerde, kişileri belirtmek için tabi olduğu millet belirtilerek Acem kızı, Arap, gâvur, Gürcü, Ermeni, Çerkez, kâfir kızı, Kürt, Urum kızı gibi sıfatlar kullanılmıştır. Bu özelliklere bakarak Elazığ-Harput bölgesinde farklı etnik grupların yan yana yaşadığını, etnik çeşitliliğin olduğu, dolayısıyla bu etnik gruplar arasında gerek dil açısından gerekse sosyal hayatta görülen gelenek ve görenek açısından bir kültür alışverişinin olduğunu söylemek mümkündür. Türküler içinde yukarıda belirtilenler dışında ahbap, hanım, hatun, dilber, dost, gakko (gakgo) ${ }^{* *}$, garip, güvey, kadın, kaltak, koca, öksüz, yeğen, yetim, yiğit gibi unvan, akrabalık adları ve lakaplar eserlerde birer kez yer alır.

\footnotetext{
${ }^{*}$ Bağmançı:(Far.T.) Bağlara bakan kimse, bağ bekçisi. Buran ve illhan, age, s. 14.

${ }^{* *}$ Gakgo:(T.) Ağabey, büyük kardeş. Buran ve İlhan, age, s. 78.
} 


\section{Sonuç}

Türküler, bir yörenin karakter ve kültürüne ışık tutan en önemli sözlü kültür öğelerinden biridir. Belirli bir ritimle söylenen şarkı, türkü, uzun hava ve gazellerde; bölgenin gelenekleri, günlük konuşma dili, toplumsal hayatı, insan ilişkileri, dini inanışları, coğrafi yapısı, geçim kaynakları ve daha pek çok konu hakkında bilgi bulunmaktadır. Bu çalışmada Elazığ ve yöresinde geçmişten günümüze söylenegelen şarkı, türkü, gazel ve uzun havadan oluşan 147 türkü incelemiştir. Araştırmanın alt amaçlarında da belirtildiği gibi yörenin musiki eserlerinin konuları tespit edilmeye çalışılmış, incelenen türkülerin 46'sının (\% 31,3) "sevda türküleri”nden oluştuğu sonucuna varılmışır. Sevda konusunu ise sırayla "dert/acı" ve "hasret" takip etmektedir. Görüldüğü üzere türkülerin büyük bölümünde (\%66.67) sevgi, sevgiden kaynaklanan özlem ve sevgiliye kavuşamamanın acısı, türkülerin büyük bölümüne konu olmuştur.

Türk kültürünün önemli bir parçası olan motifler, türkülerde de sıkça görülmektedir. Bu motiflerden en fazla kullanılanı ise "su motifi"(56 defa)dir. Bunu sırasıyla "aşk motifi" (17 defa) ve "kar motifi" (14 defa) takip etmektedir. Belirtilen bu durum, Elazığ Harput yöresine ait eserlerin bölgenin yerel özellikleri kadar Türk kültürüne ait izleri de taşıdığını göstermesi bakımından önemlidir. Anadolu'nun farklı bölgelerinde bulunan gerek sözlü gerekse yazılı eserlerde de aynı motiflerin görülmesi; kültür öğelerinin bir, aynı zamanda değişmez olduğunun göstergesidir.

Söz varlığının içerisinde bulunan ve günlük hayatta da sıkça kullanılan pek çok sözcük türkülerde de yer almaktadır. Bu sözcüklerden türküler içerisinde en fazla kullanılanları, doğa unsurları olarak ifade edilen dağ, taş, bağ; bina bölümleri olarak kabul edilen ev, kapı ve dam; ağaç, bitki ve meyve isimlerinden ise servi, elma, nar, üzüm ve gül'dür. En fazla kullanılan renk ismi kara, hayvan ismi ise bülbül, kuş ve at'tır. Bülbül (23 defa) sözcüğünün sıkça tekrar edilmesi, sözlü kültür öğelerinden aşk motifinin kullanılmasıyla bağlantılıyken kuş (11 defa) sözcüğünün görülmesi ise yaşam biçimi ve yörede görülen kuş avcılığıyla ilgili olabilir. En sık kullanılan üçüncü hayvan türü olarak at'ın (10 defa) kullanılması ise eski Türklerin yaşam biçiminde önemli bir yere sahip olmasıyla ve zamanında yörede ulaşım ve haberleşme amacıyla kullanılmasıyla açıklanabilir. Bu sözcükler, yöre halkının günlük hayatı, onlar için önemli olan kavramlar ve varlıklar hakkında bize bilgi vermektedir. Söz gelimi eserlerde bağ (16 defa) ve bahçe (12 defa) sözcüklerinin sıkça yer alması, yerel halkın tarım ve hayvancılıkla uğraştığını, günün büyük bölümünü ya evde veyahut bahçesinde geçirdiğini göstermesi bakımından önemlidir. Ev (21 defa), kapı (11 defa) ve dam (9 defa) sözcüklerinin türkülerde sıkça tekrarlanmasının sebebi de budur. Günlük hayatta en çok kullanılan mekânların türkülerde yer alması, eserlerin günlük hayattan izler taşıdığını göstermektedir.

Türkülerde yer adı olarak en sık kullanılan "Harput" kelimesi 13 eserde yer almış, dinî unsur olarak en sık kullanılan "Allah" ve "Mevla" kelimeleri sırasıyla 11 ve 8 eserde görülmüştür. Yörede tarım ürünlerinde çeşitliliğin fazla olmamasından dolayı, farklı tahıl ürünleri ile ilgili sözcükler türkülerin 
içerisinde çok az yer bulur. Bunun dışında yöreye özgü olan pestil, pekmez, gakko sözcükleri de türkülerde çok az yer bulmuştur. Yöreye özgü bu sözcüklerin diğer sözcüklere göre daha az kullanılmasının nedeni bilinmemesine rağmen, yapılacak başka bir çalışmayla bu durumun sebepleri ayrıntılı bir şekilde ortaya konabilir.

Eserlerde en fazla kullanılan sözcükler ise giyim, eşya, takı ve aksesuarla alakalı sözcüklerdir. 114 farkıı giyim, eşya, takı ve aksesuar ismi, toplamda 199 defa türkülerde yer bulur. En fazla tekrar edilen nesne ise "kına"dır (12 defa). İkinci sırada ise mendil, yastık ve yüzük aynı görülme sıklığını paylaşırlar (8 kez). Evlilik ve askere uğurlama törenlerinde kınanın çokça kullanılması, aynı zamanda kurban olarak kesilen hayvanlara da kınanın yakılması, kınanın türküler içinde fazlaca yer bulmasına neden olmuştur. Mendil, yastık ve yüzük ise günlük hayatın içerisinde sıkça kullanılırlar ve temsil ettikleri durumlara göre önem arz ederler. Mendil ve yüzük, sevgiliye verilen bir eşyalardır ve sevgiliyi temsil ettiği için kıymetlidir. Yastık, "bir yastıkta kocamak" deyiminden hareketle bazen bir temenni aracı olarak kullanılması bazen de günlük hayatta sıkça kullanılan yastık, yorgan, döşek üçlüsüne göndermede bulunması bakımından önem taşır.

Türküler içerisinde en fazla görülen isimler ise "Hayriye" ve "Mecnun"dur (üçer defa). Bu isimlerden ilki yörede yaşanan vakalardan yola çıkılarak zikredilmişken Mecnun ismi daha çok sevdiğine kavuşamayan gençleri ifade etmek için kullanılmıştır. Toplamda 70 defa görülen isimlerden Leyla/Mecnun isimleri hariç diğerlerinin hepsinin bir vakadan dolayı türkülerde yer aldığını söylemek mümkündür. Kullanılan isimlerin hepsinin bir hikâyesi vardır. Bu yönüyle türküler, bu bölgede geçmişte yaşanmış olaylar ve durumlar hakkında bize bilgiler sunmaktadır. Bütün bu özellikler göz önünde bulundurulduğunda Elazığ-Harput yöresine ait türkülerin hem yöresel hem de geleneksel kültürün izlerini taşıdığını ve taşıdığı bu izleri bunları sonraki nesillere aktararak kültür aktarımına katkıda bulunduğunu söylemek mümkündür.

\section{Kaynaklar}

Abacı, T. (2013). Harput/Elazığ Türküleri. İstanbul: ikaros Yayınları

Alpman, A. (1981, Cilt 14 Sayı 25). Hurriler. Ankara Üniversitesi Dil ve Tarih-Coğrafya Fakültesi Tarih Bölümü Tarih Araştırmaları Dergisi, s. 292-312

Ardıçoğlu, N. (1997). Harput Tarihi. Ankara: Elazığ Eğitim, Sanat, Kültür, Araştırma,Tanıtma ve Hizmet Vakfı.

Boratav, P. (2012). Türk Mitolojisi. Ankara: Bilgesu Yayıncılık.

Boratav, P. (2015). 100 Soruda Türk Folkloru. Ankara: Bilgesu Yayıncılık.

Bulut, D., \& Kazazoğlu, İ. (2012, Ocak Cilt:22 Sayı.1 ). Harput Yöresine Ait Muhalif Eserlerin Müzikal Analizi. Fırat Üniversitesi Sosyal Bilimler Dergisi , s. 209-220.

Buran, A., \& İlhan, N. (2008). Elazığ Yöresi Söz Varlığı . Ankara: Türk Dil Kurumu Yayınları. 


\section{Elazığ Harput Türküleri Üzerine Bir İnceleme}

Ekici, S. (2000). Elazığ-Harput Müzik Folkloru. Afyon: Afyon Kocatepe Üniversitesi Sosyal Bilimler Enstitüsü Yüksek Lisans Tezi.

Ekici, S. (2013, yaz Yıl:4 S. 17). Geleneksel Elazığ-Harput Müziğinde Kullanılan Makamlar . Kültür Evreni Dergisi, s. $156-168$.

Memişoğlu, F. (1966). Harput Ahengi . İstanbul: Matbaa Teknisyenleri Basımevi.

Serper, Ö. (2004). Uygulamalı Istatistik I. Bursa: Ezgi Yayınevi.

TDK. (2005). Türkçe Sözlük. Ankara: Türk Dil Kurumu Yayınları.

Ünsal, V. (2008, May Volume 1/3). M.Ö. III Binde Kuzeydoğu Anadolu. The Journel of International Social Research, s. 396-410.

Yıldırım, E., \& Pekşen, O. (2013, Aralık yıl:4 Sayı:13). Üçüncü Arami Göçü'nün Anadolu'nun Güneydoğusuna Yaptığı Etnik ve Siyasi Etkiler. Uluslararası Avrasya Sosyal Bilimler Dergisi, s. 31-55.

Yücesu, O. (1997). Harput (Elazığ) Türküleri. Ankara: Gazi Üniversitesi Sosyal Bilimler Enstitüsü Türk Dili ve Edebiyatı Bölümü Türk Halk Edebiyatı Ana Bilim Dalı Yüksek Lisans Tezi. 
Incelenen Türkülerin Listesi*

\begin{tabular}{|c|c|c|c|}
\hline Türkülerin Adı & Türkülerin Adı & Türkülerin Adı & Türkülerin Adı \\
\hline Yüksek minare $(T)$ & Tevekte üzüm kara(T) & Fatma türküsü & Deniz türküsü \\
\hline $\begin{array}{l}\text { Evlerinin önü lale } \\
\text { bağıdır(T) }\end{array}$ & Oğlan oğlan olasın(T) & Emine türküsü & Çay türküsü \\
\hline Minare dolam dolam(T) & Oğlan türküsü(T) & Mamoş türküsü & Havuzbaşı $(T)$ \\
\hline $\begin{array}{l}\text { Yağmur yağar sere } \\
\text { serpe(T) }\end{array}$ & $\begin{array}{l}\text { Kızın adı } \\
\text { Güllühan'dır(U) }\end{array}$ & Fatma ve Nuri(O) & Yel eser(T) \\
\hline $\begin{array}{l}\text { On kere sana demedim } \\
\mathrm{mi}(\text { Ş }\end{array}$ & Meste-i nazım(Ş) & Kâtip türküsü & Çay türküsü \\
\hline Evlerinin önü(T) & Sıralı dağların karı(T) & $\begin{array}{l}\text { Giderim } \\
\text { elinizden( } T \text { ) }\end{array}$ & Bu gün(T) \\
\hline $\begin{array}{l}\text { Niçin yanıma } \\
\text { gelmezsin(T) }\end{array}$ & $\begin{array}{l}\text { Hakkı'ya çıkarılan } \\
\text { türkü }\end{array}$ & Bahçeler(T) & Çayır türküsü \\
\hline Bahçeye indim ki(T) & $\begin{array}{l}\text { Bu dere baştan } \\
\text { başa(T) }\end{array}$ & Kemal türküsü & Karanfil(T) \\
\hline $\begin{array}{l}\text { Bir Leylinin } \\
\text { Mecnunuyum(T) }\end{array}$ & Gelin oldum(T) & Yemen türküsü & Kekliğim(T) \\
\hline Odasına vardım(T) & Amanın vallahi(T) & Akif türküsü & Bir dalda(T) \\
\hline Ağam mendilin hanı(T) & Telgrafın telleri(Ş) & Meteris türküsü & İki de keklik(T) \\
\hline Demedi yâr demedi(T) & Evlerinin önü(T) & Elaziz türküsü & Bülbülüm(T) \\
\hline $\begin{array}{l}\text { Yüce dağ başında armut } \\
\text { ağacı(U) }\end{array}$ & Dağlarda meşelerde(T) & $\begin{array}{l}\text { Iğki'nin dört } \\
\text { etrafı(T) }\end{array}$ & $\begin{array}{l}\text { Karanfil } \\
\text { ekilende(T) }\end{array}$ \\
\hline Yeşil yaprak arasında(T) & Esmerim türküsü & Hüseynik türküsü & Develer(T) \\
\hline $\begin{array}{l}\text { Yürü dilber } \\
\text { töremiyesin( }(T)\end{array}$ & Haktan dilerim( $\mathrm{T})$ & Harput türküsü & Mor koyun $(T)$ \\
\hline $\begin{array}{l}\text { Bir taş attım çaya } \\
\text { düşstü(T) }\end{array}$ & Çayın öte yüzünde(T) & Saray yolu(T) & Turnam(T) \\
\hline Havalandı deli gönül(T) & O yanı pembe(T) & Köğenk türküsü & Geline bak(T) \\
\hline $\begin{array}{l}\text { Dağ üstüne dağ } \\
\text { koysam(T) }\end{array}$ & Ne feryad edersin $(T)$ & Evlerinin direği $(T)$ & Karakuş(T) \\
\hline Sabahın seher vaktinde $(T)$ & Saçın türküsü & Isfihan türküsü & Sipahi(T) \\
\hline Sinemde bir tutuşmuş(S) & Yara benden(U) & Hozat türküsü & Kerem-Aslı(T) \\
\hline Al almayı benden al( $T)$ & Yola gel sevdiğim(U) & Altın yüzük (T) & Güvercin(O) \\
\hline
\end{tabular}

\footnotetext{
* Listede parantez içinde belirtilen “ $T$ ” eserin türkü olduğunu, “ $U$ ” eserin uzun hava olduğunu, “ $O$ " ise eserin oyun havası olduğunu ifade etmektedir
} 


\begin{tabular}{|l|l|l|l|}
\hline $\begin{array}{l}\text { Dersim dört dağın } \\
\text { içinde(T) }\end{array}$ & Koyunu hor eyledim(T) & $\begin{array}{l}\text { Evleri } \\
\text { görünüyor(T) }\end{array}$ & Bu dere(T) \\
\hline Bir şuh-i sitemkar(Ş) & Sürme beni(U) & Fincan türküsü & Gamzedeler(U) \\
\hline $\begin{array}{l}\text { Kar mı yağmış̧̧ } \\
\text { Harput'un başına(T) }\end{array}$ & $\begin{array}{l}\text { Ne mestim ne } \\
\text { sarhoşum(U) }\end{array}$ & $\begin{array}{l}\text { Nayim (Naim) } \\
\text { türküsü }\end{array}$ & $\begin{array}{l}\text { Pisik (Kedi) } \\
\text { oyunu }\end{array}$ \\
\hline Humar Gözlüm(U) & Kara dutun dalını (T) & Al çuha türküsü & Yüzük oyunu \\
\hline $\begin{array}{l}\text { Görmedim âlemde bir } \\
\text { benzerin(Ş) }\end{array}$ & $\begin{array}{l}\text { Gelin ağlar yaşın yaşın } \\
\text { (O) }\end{array}$ & $\begin{array}{l}\text { Karşıda Kürt } \\
\text { evleri(T) }\end{array}$ & $\begin{array}{l}\text { Sudan } \\
\text { geçirme(O) }\end{array}$ \\
\hline Yoğurt koydum dolaba(T) & Yâr yad oldum(U) & Mendil türküsü & Delilo(O) \\
\hline Kaşların karasına(T) & Mendilim isle yolla (T) & Nesibe türküsü & Tamzara(O) \\
\hline İndim yârin bahçesine(T) & Hafo (Hafize) türküsü & $\begin{array}{l}\text { Oyalı yazma başı } \\
\text { (T) }\end{array}$ & Çayda Çıra(O) \\
\hline Değirmen sala benzer(T) & Duriye türküsü & Yazma türküsü & Bağ altına(O) \\
\hline Kala meydanının düzü(T) & Hayriye türküsü & Puşu türküsü & Uy bıçağım(T) \\
\hline $\begin{array}{l}\text { Bugün dersin yarın dersin } \\
\text { (U) }\end{array}$ & Hop hop nanay (T) & Gökte yıldız (T) & Çikçiko(O) \\
\hline Kemer ağır kalkmıyor(T) & $\begin{array}{l}\text { Dere boyu düz gider } \\
\text { (T) }\end{array}$ & Zeynep türküsü & Kama türküsü \\
\hline Bağlarda çemen soldu(Ş) & Feridem (meşelidir) (T) & Kar (T) & Fide türküsü \\
\hline Meclisinde mail oldum(Ş) & Necibem türküsü & Dağlar (T) & Kürdün kızı(T) \\
\hline Aş yedim dilim yandı(T) & Ahçiği yolladım (T) & Geldi geçti yâr(U) & Karşılama(T) \\
\hline $\begin{array}{l}\text { Gönül yükseklenmiş } \\
\text { alçaklayamam(U) }\end{array}$ & $\begin{array}{l}\text { Derya kenarına bir ev } \\
\text { yapmışam(T) }\end{array}$ & $\begin{array}{l}\text { Yüzük oyunu } \\
\text { türküsü }\end{array}$ & \\
\hline
\end{tabular}

